Research Article

\title{
Segmental Modification of the Mualem Model by Remolded Loess
}

\author{
Le-fan Wang, ${ }^{1}$ Xing-zhong Weng, ${ }^{1}$ Zhi-hua Yao, ${ }^{1}$ \\ Ren-yi Zhang, ${ }^{1}$ Wan $\mathrm{Li},{ }^{1}$ and $\mathrm{Ye} \mathrm{Li}^{2}$ \\ ${ }^{1}$ Department of Airport Engineering and Architecture, Air Force Engineering University, Xian 710038, China \\ ${ }^{2}$ School of Economics and Management, Chang'an University, Xian, Shaanxi 710064, China
}

Correspondence should be addressed to Le-fan Wang; 329873077@qq.com

Received 1 November 2016; Accepted 26 December 2016; Published 15 January 2017

Academic Editor: Konstantinos Karamanos

Copyright (C) 2017 Le-fan Wang et al. This is an open access article distributed under the Creative Commons Attribution License, which permits unrestricted use, distribution, and reproduction in any medium, provided the original work is properly cited.

\begin{abstract}
The measured diffusion coefficient and soil-water characteristic curve (SWCC) of remolded loess were used to modify the Mualem model for increasing its accuracy. The obtained results show that the goodness of fit between the Mualem model and the variable parameter-modified Mualem method comparing with the test results was not high. The saturation of 0.65 was introduced as the boundary to divide the curve of the measured diffusion coefficient into two segments. When the segmentation method combined with the variable parameter method was used to modify the Mualem model, the fitting correlation coefficient was increased to 0.921-0.998. The modified parameters $K_{o}$ and $L$ corresponding to remolded loess were calculated for different dry densities. Based on the exponential function between $K_{o}$ and dry density and the linear relation between $L$ and dry density, the segmentally modified Mualem model was established for remolded loess by considering variation in dry density. The results of the study can be used for directly determining the unsaturated infiltration coefficient and for indirectly determining the SWCC through diffusion coefficient.
\end{abstract}

\section{Introduction}

The unsaturated infiltration coefficient is an important content in the study of unsaturated soil and is commonly predicted by using the soil-water characteristic curve (SWCC). Childs and Collis-George [1], Marshall [2], Xu [3], and Mei et al. [4] have achieved lots of beneficial results in the field of unsaturated infiltration coefficient prediction. Mualem [5] proposed a model, widely known as the Mualem model, for unsaturated infiltration coefficient prediction by studying 45 groups of undisturbed soil and remolded soil in 1976, which has been widely applied.

The saturated infiltration coefficient $K_{s}$ is an important parameter of the Mualem model. Van Genuchten and Nielsen [6] believed that $K_{s}$ mainly reflects the characteristic of moisture flow in soil pores incurred by external force, while unsaturated seepage is mainly caused by the matrix suction inside the soil mass. Schaap and Leij [7], by analyzing 235 groups of soil sample, stated that the saturated infiltration coefficient $K_{s}$ in the Mualem model should be replaced by the modified infiltration coefficient $K_{o}$ and that $K_{o}$ is one order of magnitude smaller than $K_{s}$.

Another important parameter $L$ of the Mualem model was originally fixed at 0.5 [5]. However, Yates et al. [8] found the $L$ value can be a variable greater than -3.31 by reanalyzing the data of Mualem in 1976. Likewise, Schuh and Cline [9] obtained the $L$ value between -8.73 and 14.80 through analyzing 75 groups of data. It is found in these papers [6-9] that setting all the parameters of the Mualem model as fixed values reduces the model's accuracy in predicting the unsaturated infiltration coefficient. Valiantzas [10] combined Brooks-Corey and Van Genuchten closed-form models improving prediction of conductivity values near the residual water content and saturation. Hu et al. [11] developed a new soil-water characteristic curve model for deformable soils. Zhang et al. [12] improved the accuracy of saturated hydraulic conductivity in the Mualem model.

The unsaturated infiltration coefficient can also be of either the SWCC method or the diffusion coefficient method [13]. Wang et al. [14] and Yao et al. [15] used this method 
to analyze the infiltration characteristic of loess. Guided by the idea of integrating the above two methods of determining the unsaturated infiltration coefficient, this study conducted a horizontal one-dimensional (1D) seepage test to measure the diffusion coefficient and used SWCCs of remolded loess of different dry densities to modify the Mualem model. Subsequently, this paper proposes a dry density-based, remolded loess-modified Mualem model.

\section{Theoretical Basis}

2.1. Mualem Model and Proposed Modification of Its Variable Parameters. The Mualem model for predicting the unsaturated infiltration coefficient is presented as follows:

$$
K(\theta)=K_{s} S_{e} 0.5\left(\frac{\int_{0}^{S_{e}} \psi\left(S_{e}\right)^{-1} d S_{e}}{\int_{0}^{1} \psi\left(S_{e}\right)^{-1} d S_{e}}\right)^{2}
$$

where $K_{s}$ is the saturated infiltration coefficient and $\psi\left(S_{e}\right)$ is the matrix suction corresponding to the effective saturation $S_{e}$.

On the other hand, Hoffmann-Riem proposed a universal model for predicting the unsaturated infiltration coefficient in 1999 as follows:

$$
K(\theta)=K_{o} S_{e}{ }^{L}\left(\frac{\int_{0}^{S_{e}} \psi^{-\beta} d S_{e}}{\int_{0}^{1} \psi^{-\beta} d S_{e}}\right)^{\gamma} .
$$

The present paper set $\beta=1$ and $\gamma=2$ in (2) in correspondence with the Mualem model. This is equivalent to introducing two variable parameters, $K_{o}$ and $L$, in the original Mualem model to obtain a diffusion coefficient-modified Mualem model.

\subsection{Determination of the Diffusion Coefficient by Horizontal} $1 D$ Seepage Test [13]. Without considering the action of gravity or the deformation of soil mass, the differential equation and boundary conditions for moisture movement in the horizontal 1D seepage test without free head are shown as follows:

$$
\begin{aligned}
\frac{\partial \theta}{\partial t} & =\frac{\partial}{\partial}\left[D(\theta) \frac{\partial \theta}{\partial x}\right], \\
\theta & =\theta_{a} \quad x>0, t=0, \\
\theta & =\theta_{o} \quad x=0, t>0,
\end{aligned}
$$

where $\theta$ is the volumetric moisture content $\left(\mathrm{cm}^{3} \cdot \mathrm{cm}^{-3}\right), D(\theta)$ is the diffusion coefficient $\left(\mathrm{cm}^{2} \cdot \mathrm{min}^{-1}\right), x$ is the distance from the water inlet $(\mathrm{cm}), \theta_{a}$ and $\theta_{o}$ are, respectively, the initial volumetric moisture content of soil sample and the volumetric moisture content at water inlet $\left(\mathrm{cm}^{3} \cdot \mathrm{cm}^{-3}\right)$, and $t$ is the infiltration time ( $\mathrm{min}$ ).

After measuring the distribution of the volumetric moisture content $\theta$ of soil columns at time $t, \lambda(\theta) \sim \theta$ can be calculated according to the Boltzmann parameter as $\lambda(\theta)=$ $x t^{-0.5}$. The diffusion coefficient $D(\theta)$ can be calculated as follows:

$$
D(\theta)=-\frac{1}{2} \frac{\Delta \lambda}{\Delta \theta} \sum_{\theta_{a}}^{\theta} \lambda d \theta .
$$

The relationship among the diffusion coefficient $D(\theta)$, the SWCC $\psi(\theta)$, and the infiltration coefficient $K(\theta)$ is given as

$$
K(\theta)=-D(\theta) \cdot \frac{d \theta}{d \psi(\theta)} .
$$

After measuring the diffusion coefficient and the SWCC, the unsaturated infiltration coefficient can be calculated from (7).

2.3. SWCC Model. In order to modify the Mualem model, the first step is to determine the SWCC model. For this purpose, the present paper adopted the Brook and Corey model, as shown below:

$$
\begin{aligned}
& \frac{\theta-\theta_{r}}{\theta_{s}-\theta_{r}}=S_{e}=1, \quad \psi \leq \psi_{a}, \\
& \frac{\theta-\theta_{r}}{\theta_{s}-\theta_{r}}=S_{e}=\left(\frac{\psi_{a}}{\psi}\right)^{\sigma}, \quad \psi>\psi_{a},
\end{aligned}
$$

where $\sigma$ is the shape parameter of the SWCC, $\theta_{s}$ is the saturated volumetric moisture content, $\theta_{r}$ is the residual volumetric moisture content, and $\psi_{a}$ is the air entry value.

\section{Issues Related to the Modification of Mualem Model}

3.1. Calculation Method of Modified Parameters. The unsaturated infiltration coefficient can be calculated after measuring the SWCC and the diffusion coefficient in the test. The Mualem model was modified directly based on the measured diffusion coefficient in this paper to reduce the steps of calculating the unsaturated infiltration coefficient and to avoid the accumulation of errors in the calculation process.

A relational expression for the diffusion coefficient and the volumetric moisture content can be obtained, through transformation, by substituting (7) and (9) into (5):

$$
D(\theta)=\frac{\psi_{a}}{\sigma\left(\theta_{s}-\theta_{r}\right)} K_{o}\left(\frac{\theta-\theta_{r}}{\theta_{s}-\theta_{r}}\right)^{1+L+1 / \sigma} .
$$

After obtaining the parameters of (10) through curve fitting the diffusion coefficient and volumetric moisture content measured in the horizontal 1D seepage test, we can substitute the SWCC parameters to calculate the modified parameters $K_{o}$ and $L$ of the diffusion coefficient-modified Mualem model.

3.2. Requirements on Horizontal 1D Seepage Test. The diffusion coefficient-modified Mualem model, as discussed in Section 3.1, actually combines the two methods of indirectly determining the unsaturated infiltration coefficient. As indicated by (10), the diffusion coefficient of soil sample was 
TABLE 1: Physical properties of remolded loess.

\begin{tabular}{lcccc}
\hline Particulate density/g. $\mathrm{cm}^{-3}$ & Mass moisture content/\% & $W_{P} / \%$ & $W_{L} / \%$ & \\
\hline 2.71 & 6.3 & 17.6 & $I_{P}$ \\
\hline
\end{tabular}

zero when the volumetric moisture content was equal to or lower than the residual moisture content. In the horizontal 1D seepage test, the diffusion coefficient corresponding to the initial moisture content of soil sample was zero, so the combination of these two methods must satisfy

$$
\theta_{r}=\theta_{o}
$$

The residual moisture content $\theta_{r}$ is an important parameter of the SWCC, so, in the horizontal 1D seepage test, the initial moisture content of soil sample should be precontrolled to be approximately equal to the residual moisture content.

\section{Modification of the Mualem Model}

4.1. Test Introduction. The loess used in the test was collected from Heping Town in Ningxia Province at a depth of 2-3 m. The horizontal $1 \mathrm{D}$ seepage test was carried out in an organic glass tube $186 \mathrm{~mm}$ in inner diameter and 1,000 $\mathrm{mm}$ in length, and the soil sample was placed in the organic glass tube in layers of $5 \mathrm{~cm}$ thickness and was compacted until the set dry density was achieved. A Mariotte bottle was used to supply water for the seepage test, and the free head was controlled at $10 \mathrm{~cm}$. According to the literature [16], the SWCC was determined in the horizontal 1D seepage process with the preembedded TDR moisture meter and Fredlund thermal conduction suction probe jointly. After 10-12 hours of water supply and seepage, the soil sample was sliced and dried to calculate the diffusion coefficient.

The loess used in the test was naturally air-dried loess, and its physical parameters are shown in Table 1. According to the residual moisture content of remolded loess in [9] and the method of measuring the residual moisture content in [17], it was confirmed that the initial moisture content of soil sample had satisfied relevant requirements. Figure 1 shows the relationship between the diffusion coefficient and saturation $S$ and Figure 2 shows the measured SWCC.

The measured SWCC was fitted according to the Brook and Corey model. The resulting parameters are shown in Table 2.

According to Table 2, the correlation coefficient $R^{2}$ between the Brook and Corey model data and the measured SWCC data exceeded 0.95, confirming that the Brook and Corey model applies to the remolded loess used in the test and suggesting that the initial moisture content had been appropriately controlled.

\subsection{Applicability Test of Mualem Model and Variable Param-} eter Modification Method. Before modification, the applicability of the Mualem model and the variable parameter modification method was tested, thus to demonstrate the necessity of modification. The measured diffusion coefficient was fitted by (10), as shown in Figure 3.

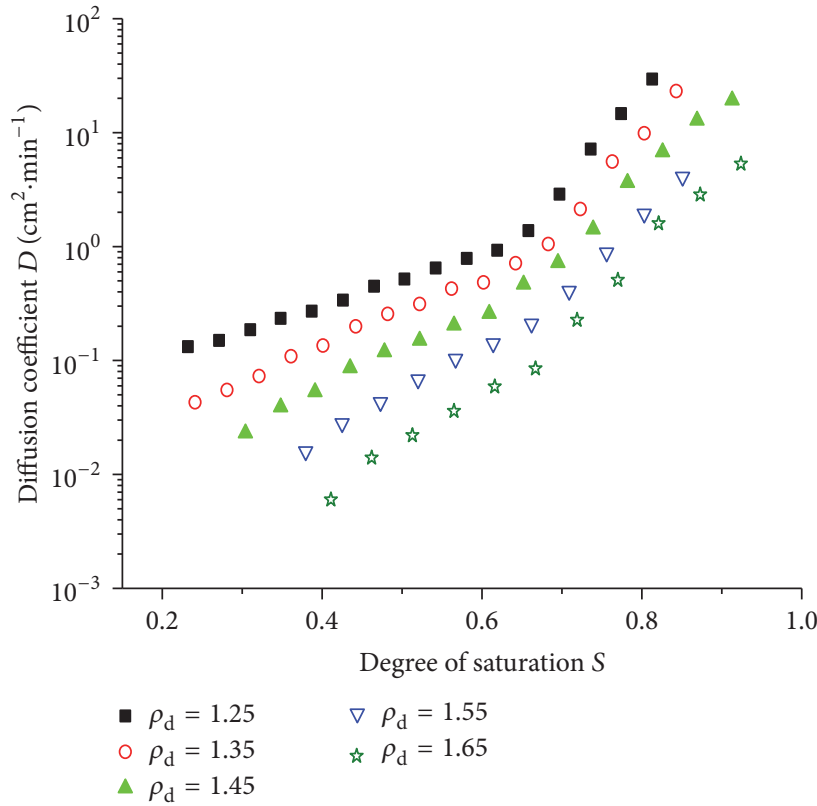

Figure 1: Diffusion coefficient under different dry densities.

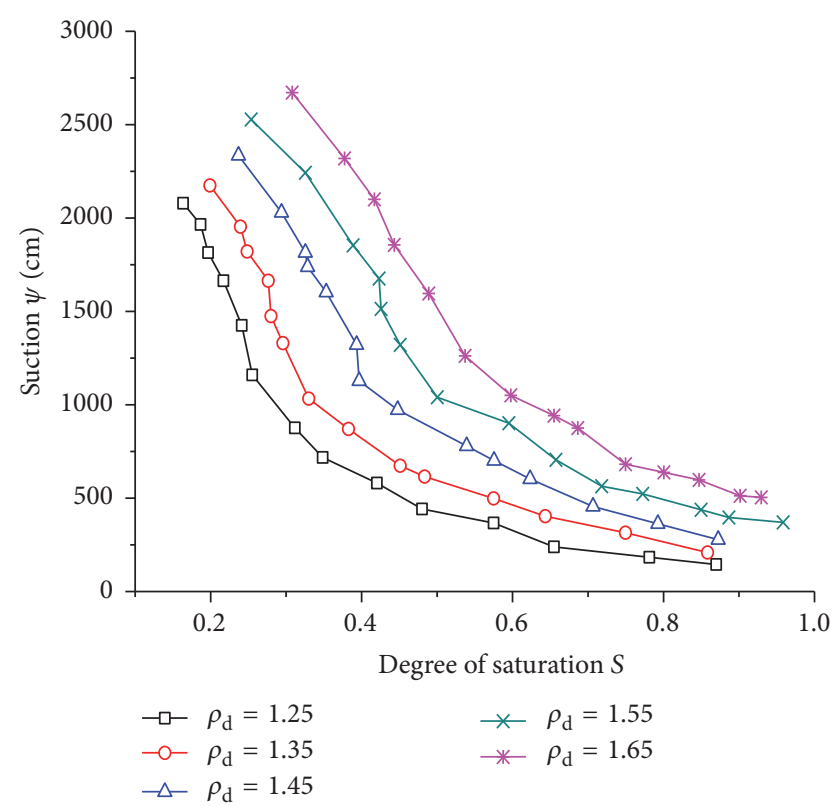

FIGURE 2: SWCC under different dry densities.

The modified parameters $K_{o}$ and $L$ of (7) were then calculated on the basis of Table 3 .

Figure 3 and Table 3 indicated that (i) the goodness of fit between (10) and the measured diffusion coefficient increased with an increase in dry density, (ii) the modified 
TABLE 2: SWCC fitting parameters.

\begin{tabular}{|c|c|c|c|c|c|}
\hline Dry density $/ \mathrm{g} \cdot \mathrm{cm}^{-3}$ & $\theta_{s} / \mathrm{cm}^{3} \cdot \mathrm{cm}^{-3}$ & $\theta_{r} / \mathrm{cm}^{3} \cdot \mathrm{cm}^{-3}$ & $\psi_{a} / \mathrm{cm}$ & $1 / \sigma$ & $R^{2}$ \\
\hline 1.25 & 0.539 & 0.079 & 169 & 0.90 & 0.956 \\
\hline 1.35 & 0.502 & 0.083 & 227.91 & 0.94 & 0.978 \\
\hline 1.45 & 0.465 & 0.091 & 290 & 1.01 & 0.972 \\
\hline 1.55 & 0.428 & 0.098 & 373.79 & 0.98 & 0.972 \\
\hline 1.65 & 0.391 & 0.104 & 487.7 & 0.91 & 0.981 \\
\hline
\end{tabular}

TABLE 3: Modified parameters $K_{o}$ and $L$.

\begin{tabular}{lccc}
\hline Dry density $/ \mathrm{g} \cdot \mathrm{cm}^{-3}$ & $K_{o} / \mathrm{cm}^{2} \cdot \mathrm{min}^{-1}$ & $L$ & $R^{2}$ \\
\hline 1.25 & $1.95 E-02$ & 1.39 & 0.726 \\
1.35 & $1.02 E-02$ & 1.63 & 0.790 \\
1.45 & $9.76 E-03$ & 2.46 & 0.852 \\
1.55 & $2.83 E-03$ & 2.66 & 0.902 \\
1.65 & $1.82 E-03$ & 3.53 & 0.908
\end{tabular}

parameter $K_{o}$ diminished with an increase in dry density, and (iii) the modification coefficient $L$ increased with an increase in dry density. Two conclusions can be drawn. First, the Mualem model could not be directly applied to the remolded loess used in the test, as (2) had set $\beta$ and $\gamma$ in correspondence with the Mualem model and the $L$ value obtained through curve fitting ranged between 1.39 and 3.53, which is significantly different from the $L$ value of 0.5 in the Mualem model. Second, the method of purely introducing the variable parameters $K_{o}$ and $L$ to modify the Mualem model also needed to be improved, as the correlation between (10) and the measured diffusion coefficient was not high (the correlation coefficient ranging only between 0.726 and 0.908).

4.3. Segmental Modification of the Mualem Model. The low goodness of fit between the method of modifying the Mualem model with variable parameters and the measured value shown in Figure 1 is due to the abrupt change in the diffusion coefficient of soil around a degree of saturation of 0.65 , which has also been demonstrated by Chen et al. [18] through experimental tests.

As can be found from the analysis of Figure 1, the diffusion coefficient of the two individual segments before and after the degree of saturation of 0.65 and (10) had similar curve shapes. Thus, the measured diffusion coefficient was split into two segments separated at the degree of saturation of 0.65 , and the Mualem model was segmentally modified by (10). The resulting curve fitting parameters are shown in Figure 4.

As shown in Figures 3 and 4, the segmental modification method combined with the variable parameter method significantly increased the goodness of fit between the Mualem model data and the measured values. The modified parameters $K_{o}$ and $L$ of the modified Mualem models corresponding to various dry densities of the two segments were calculated based on Table 3 and are shown in Table 4.

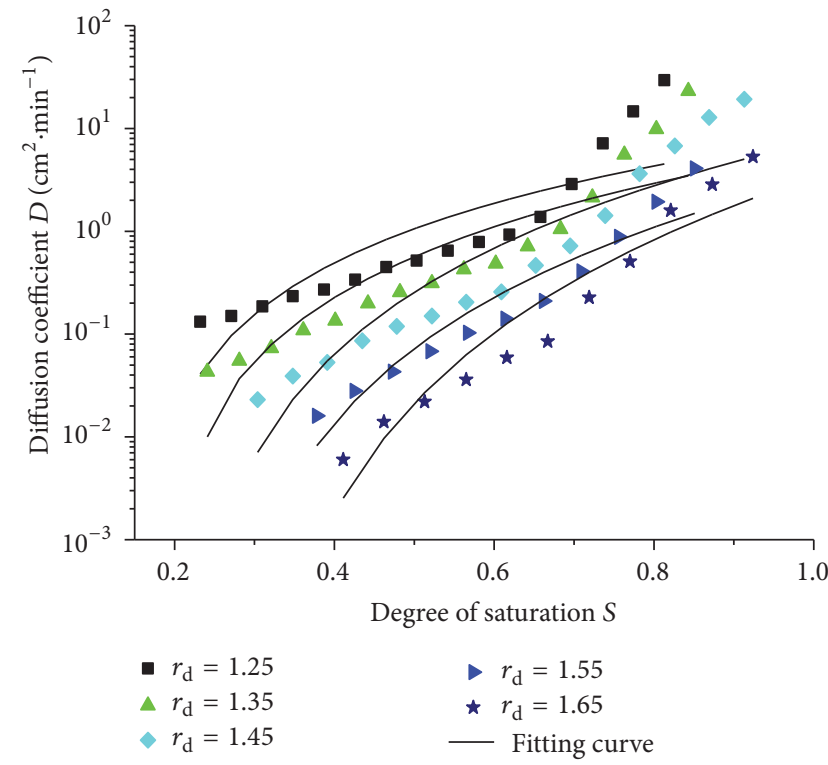

FIgURE 3: Curve fitting for the diffusion coefficient.

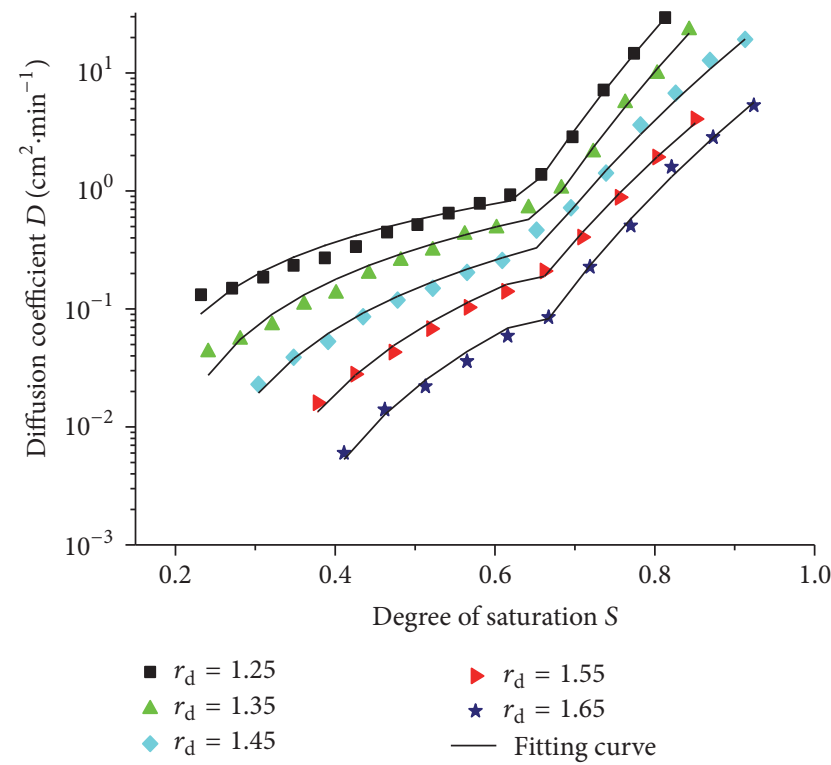

FIgURE 4: Piecewise fitting of the diffusion coefficient. 
TABLE 4: Modified parameters of piecewise fitting.

\begin{tabular}{|c|c|c|c|c|c|c|}
\hline \multirow{2}{*}{ Dry density $/ \mathrm{g} \cdot \mathrm{cm}^{-3}$} & \multicolumn{3}{|c|}{ Segment less than 0.65 in saturation } & \multicolumn{3}{|c|}{ Segment above 0.65 in saturation } \\
\hline & $K_{o} / \mathrm{cm}^{2} \cdot \mathrm{min}^{-1}$ & $L$ & $R^{2}$ & $K_{o} / \mathrm{cm}^{2} \cdot \min ^{-1}$ & $L$ & $R^{2}$ \\
\hline 1.25 & $4.34 E-03$ & 0.39 & 0.921 & 1.31 & 10.83 & 0.998 \\
\hline 1.35 & $2.51 E-03$ & 0.72 & 0.940 & 0.41 & 10.51 & 0.995 \\
\hline 1.45 & $1.32 E-03$ & 0.96 & 0.972 & $7.27 E-02$ & 8.22 & 0.990 \\
\hline 1.55 & $8.65 E-04$ & 1.64 & 0.973 & $1.93 E-02$ & 7.29 & 0.994 \\
\hline 1.65 & $3.21 E-04$ & 2.00 & 0.962 & $7.68 E-03$ & 7.62 & 0.995 \\
\hline
\end{tabular}

TABLE 5: Expressions between the modified parameters and dry density.

\begin{tabular}{lcr}
\hline Modified parameter & Relational expression with dry density & $R^{2}$ \\
\hline Segment when saturation is less than 0.65 & $K_{o}=0.04 \times \rho_{d}{ }^{-9}$ & 0.974 \\
& $L=5.31 \times \rho_{d}-5.37$ & 0.959 \\
Segment when saturation is greater than 0.65 & $K_{o}=103.87 \times \rho_{d}{ }^{-19.24}$ & 0.994 \\
& $L=-9.64 \times \rho_{d}+22.87$ & 0.844 \\
\hline
\end{tabular}

As shown in Table 4, $K_{o}$ always diminished with an increase in dry density. However, $L$ showed opposing trends in the two saturation segments for variation with an increase in dry density. In the curve fitting, the correlation coefficient ranged from 0.921 to 0.998 . The results obtained by introducing the variable parameters $K_{o}$ and $L$ and adopting the saturation of 0.65 as the boundary for the segmental modification of the Mualem model fitted well with the test results.

There are three types of unsaturated soil corresponding to three types of water connection states and transmission pressure capacities. Thus, the diffusion coefficient may also present a three-segment variation law. In the present paper, the initial moisture content of the horizontal 1D seepage test sample was controlled to be approximately equal to the residual moisture content. Moreover, the diffusion coefficients measured were the diffusion coefficients of the double-open unsaturated soil and gas-sealed unsaturated soil. Thus, good results were achieved by dividing the diffusion coefficient into two segments.

\section{The Mualem Model Modified by the Unsaturated Infiltration Coefficient of Loess}

5.1. Combination of the Prediction Method and the Calculation Method for Determining the Unsaturated Infiltration Coefficient. Among the unsaturated infiltration coefficient, the SWCC, and the diffusion coefficient, there are two independent parameters. The first method, the prediction method, based on the assumption of the continuous distribution of soil pores, directly establishes the relationship between the SWCC and the unsaturated infiltration coefficient. The second method, the calculation method, solves the problem on the basis of the relationships among the three. The above two methods of determining the unsaturated infiltration coefficient both require the measurement of the SWCC. When the prediction method is combined with the calculation method and the parameters $K_{o}$ and $L$ in (10) are given, the expressions of the unsaturated infiltration coefficient and the SWCC can be simultaneously obtained from the measured diffusion coefficient. When compared to the SWCC, the diffusion coefficient can be more easily determined.

The combination of the two methods simplifies the determination of the unsaturated infiltration coefficient and the SWCC. The key lies in selecting reasonable prediction method for unsaturated infiltration coefficient. Modifying a prediction model for the unsaturated infiltration coefficient can not only increase the accuracy in predicting the unsaturated infiltration coefficient, but also lower the requirements imposed by the unsaturated soil seepage parameter test on test instruments and equipment.

5.2. Dry Density-Based Modified Mualem Model. It is found in the analysis that $K_{o}$ and dry density show a power exponential relationship, while $L$ and dry density show a linear relationship. For reference, the fitting charts are shown in Figures 5 and 6, and the fitting equations are shown in Table 5.

By substituting the fitting equations in Table 5 into (1), the segmentally modified Mualem model can be obtained for the unsaturated infiltration coefficient of remolded loess. The model considers the variation in the unsaturated infiltration coefficient with the dry density of remolded loess and can be expressed as

$$
K(\theta)=a \rho_{d}^{b} S_{e}^{c \rho_{d}-d}\left(\frac{\int_{0}^{S_{e}} \psi^{-1} d S_{e}}{\int_{0}^{1} \psi^{-1} d S_{e}}\right)^{2},
$$

where parameters $a, b, c$, and $d$ can be found in Table 5 .

\section{Conclusions}

Taking advantage of its simple form, the Mualem model has been widely applied to the prediction of the unsaturated infiltration coefficient. In this paper, an applicability test and a modification in the Mualem model were performed through an experiment. The main conclusions are as follows: 


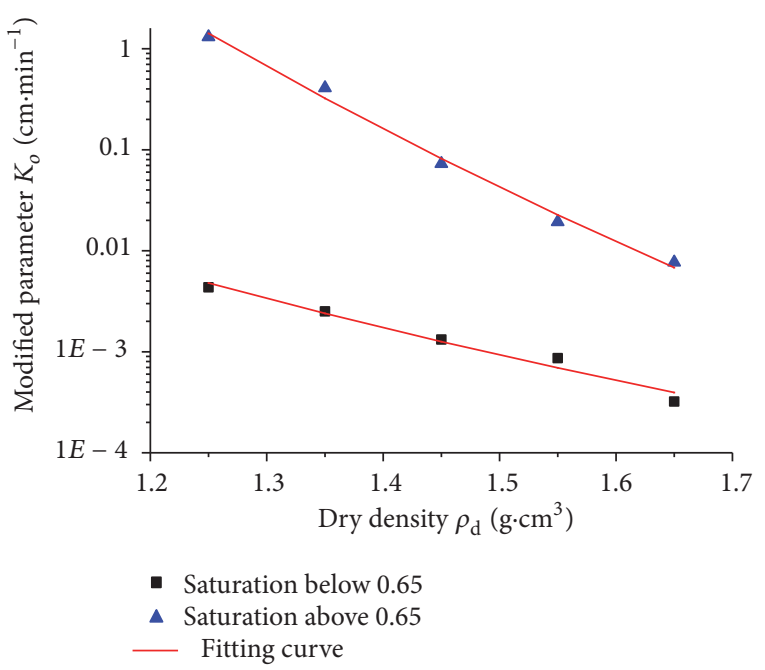

FIGURE 5: Relationship between the modified parameter $K_{o}$ and dry density.

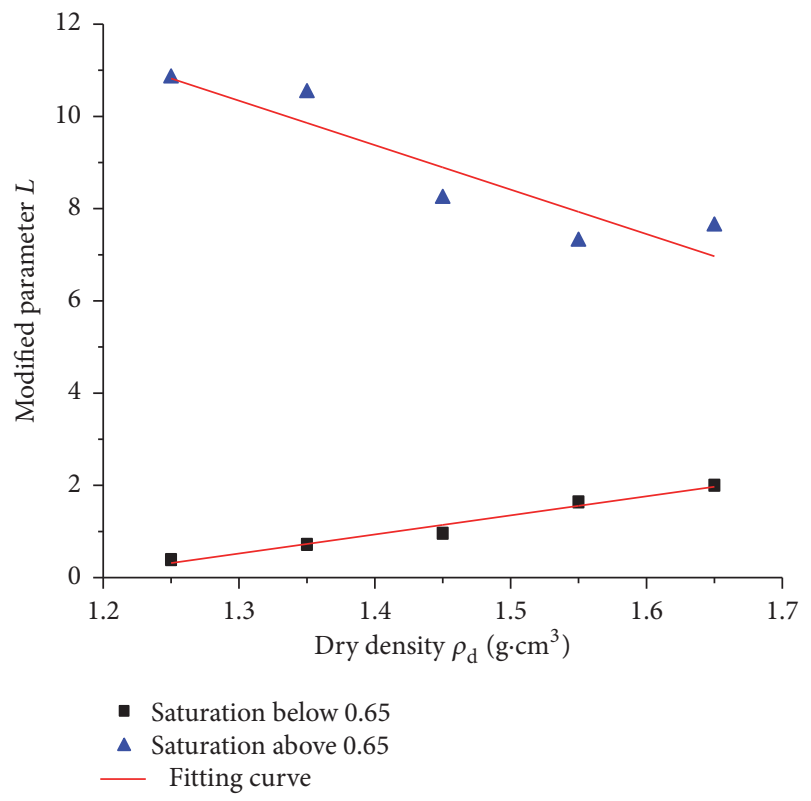

Figure 6: Relationship between the modified parameter $L$ and dry density.

(1) The results of the applicability analysis of the Mualem model indicated that the Mualem model could not be satisfactorily applied to the remolded loess tested in the present paper. The method of introducing only two variable parameters $K_{o}$ and $L$ for modifying the Mualem model had a low correlation coefficient with the measured value.

(2) An abrupt change in the diffusion coefficient was observed corresponding to a saturation of 0.65 . This was attributed to the change in water connection state in unsaturated soil.

(3) When the saturation of 0.65 was adopted as the boundary to divide the curve of measured diffusion coefficient into two segments, the fitting correlation coefficient ranged from 0.921 to 0.998 . The approach of combining the segmental modification method and the variable parameter method fitted well with the test results. This paper obtained the values of modified parameters $K_{o}$ and $L$ corresponding to remolded loess of five dry densities.

(4) Based on the power exponential function between $K_{o}$ and dry density and the linear relationship between $L$ and dry density, a segmentally modified Mualem model was established by considering dry density changes of remolded loess.

\section{Competing Interests}

The authors declare that there is no conflict of interests regarding the publication of this paper.

\section{Acknowledgments}

This paper is supported by the National Natural Science Foundation of China (Project: 51509257).

\section{References}

[1] E. C. Childs and N. Collis-George, "The permeability of porous materials," Proceedings of the Royal Society A: Mathematical, Physical and Engineering Sciences, vol. 201, no. 1066, pp. 392405, 1950.

[2] T. J. Marshall, "A relation between permeability and size distribution of pores," Journal of Soil Science, vol. 9, no. 1, pp. $1-8,1958$.

[3] Y. Xu, "Calculation of unsaturated hydraulic conductivity using a fractal model for the pore-size distribution," Computers and Geotechnics, vol. 31, no. 7, pp. 549-557, 2004.

[4] G.-X. Mei, Q.-M. Chen, and P.-M. Jiang, "Stress-strain relationship of unsaturated cohesive soil," Journal of Central South University of Technology, vol. 17, no. 3, pp. 653-657, 2010.

[5] Y. Mualem, "A new model for predicting the hydraulic conductivity of unsaturated porous media," Water Resources Research, vol. 12, no. 3, pp. 513-522, 1976.

[6] M. T. Van Genuchten and D. R. Nielsen, "On describing and predicting the hydraulic properties of unsaturated soils," Annales Geophysicae, vol. 3, no. 5, pp. 615-628, 1985.

[7] M. G. Schaap and F. J. Leij, "Improved prediction of unsaturated hydraulic conductivity with the Mualem-van Genuchten model," Soil Science Society of America Journal, vol. 64, no. 3, pp. 843-851, 2000.

[8] S. R. Yates, M. T. Van Genuchten, A. W. Warrick, and F. J. Leij, "Analysis of measured, predicted, and estimated hydraulic conductivity using the RETC computer program," Soil Science Society of America Journal, vol. 56, no. 2, pp. 347-354, 1992.

[9] W. M. Schuh and R. L. Cline, "Effect of soil properties on unsaturated hydraulic conductivity pore- interaction factors," Soil Science Society of America Journal, vol. 54, no. 6, pp. 1509$1519,1990$.

[10] J. D. Valiantzas, "Combined Brooks-Corey/Burdine and van Genuchten/Mualem closed-form model for improving prediction of unsaturated conductivity," Journal of Irrigation and Drainage Engineering, vol. 137, no. 4, pp. 223-233, 2011. 
[11] R. Hu, Y. Chen, and C. Zhou, "A relative hydraulic conductivity model for unsaturated deformable soils," Chinese Journal of Rock Mechanics and Engineering, vol. 32, no. 6, pp. 1279-1287, 2013.

[12] H. Zhang, Q. Gu, and R. Zhang, "Modification of saturated hydraulic conductivity in mualem model," Bulletin of Soil and Water Conservation, vol. 35, no. 3, pp. 168-171, 2015.

[13] Z. Lei, S. Yang, and S. Xie, Soil Water Dynamics, Tsinghua University Press, Beijing, China, 1988.

[14] T. Wang, J. Lu, and J. Zhang, "Experimental study on permeability coefficient of artificially compacted unsaturated loess considering influence of density," Chinese Journal of Rock Mechanics and Engineering, vol. 25, no. 11, pp. 2364-2368, 2006.

[15] Z.-H. Yao, Z.-H. Chen, X.-F. Huang, S.-J. Zhang, and X.-H. Yang, "Hydraulic conductivity of unsaturated undisturbed and remolded Q3 loess," Chinese Journal of Geotechnical Engineering, vol. 34, no. 6, pp. 1020-1027, 2012.

[16] W. Wang and J. Zhang, "Study and application of infiltration experimental equipment for one-dimensional soil column in laboratory," Acta Pedologica Sinica, vol. 28, no. 4, pp. 447-451, 1991.

[17] Z. Li, T. Li, and R. Hu, "Methods for testing and predicting of SWCC in unsaturated soil mechanics," Journal of Engineering Geology, vol. 15, no. 5, pp. 700-707, 2007.

[18] Z. Chen, D. Xie, and Y. Wang, "Experimental studies of laws of fluids motion,suction and pore pressures in unsaturated soils," Chinese Journal of Geotechnical Engineering, vol. 15, no. 3, pp. 9-20, 1993. 


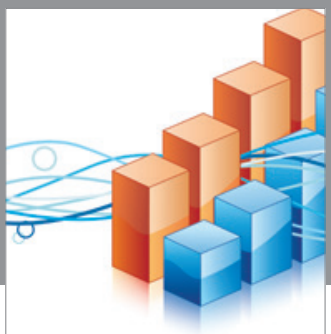

Advances in

Operations Research

vatem alat4

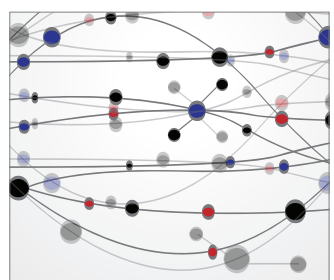

\section{The Scientific} World Journal
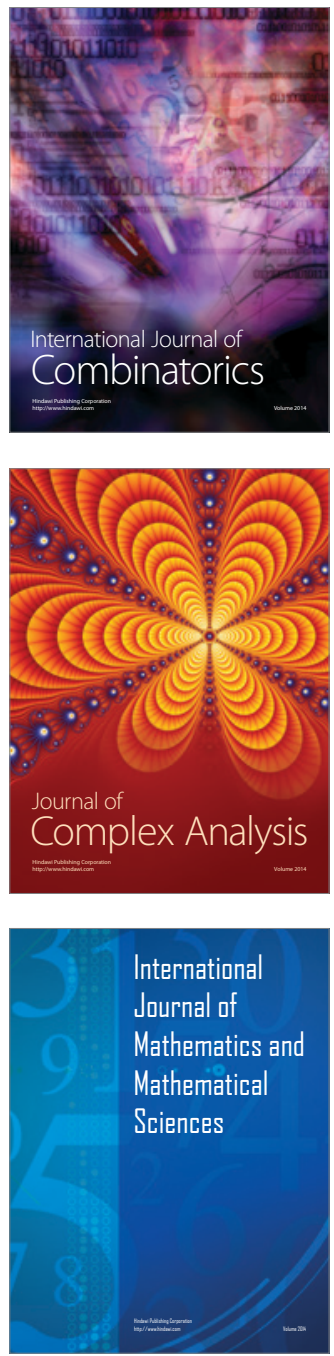
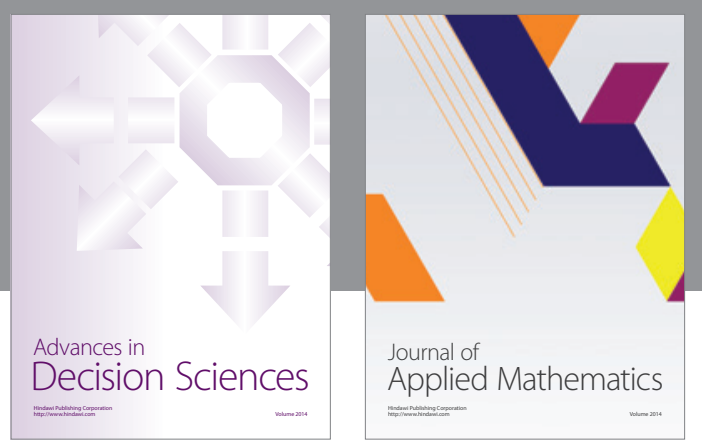

Algebra

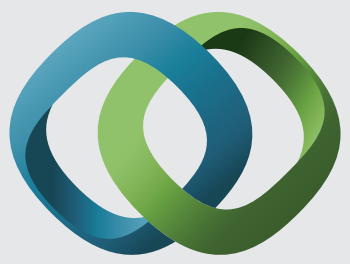

\section{Hindawi}

Submit your manuscripts at

https://www.hindawi.com
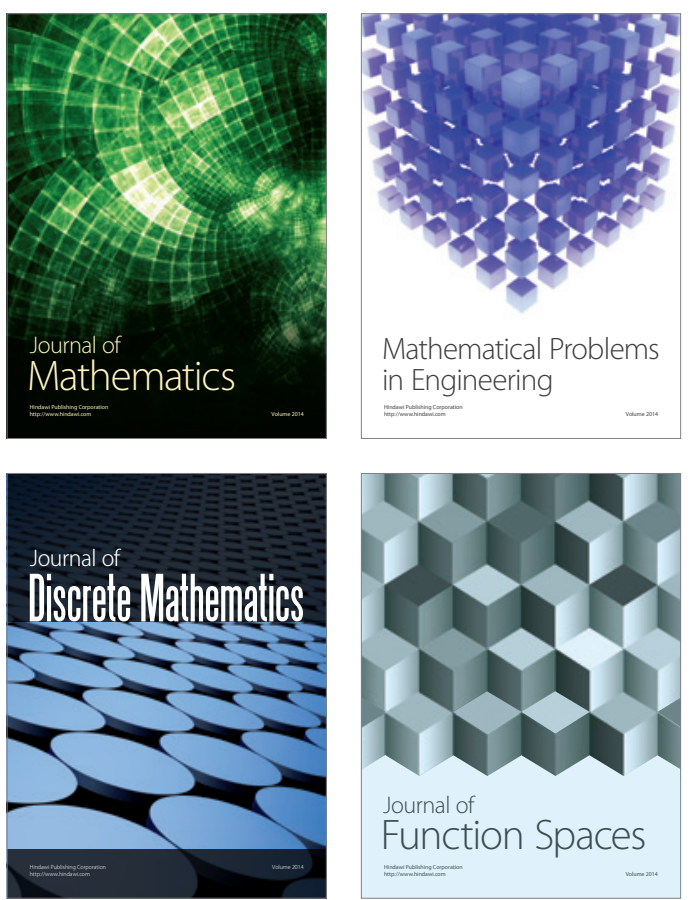

Mathematical Problems in Engineering
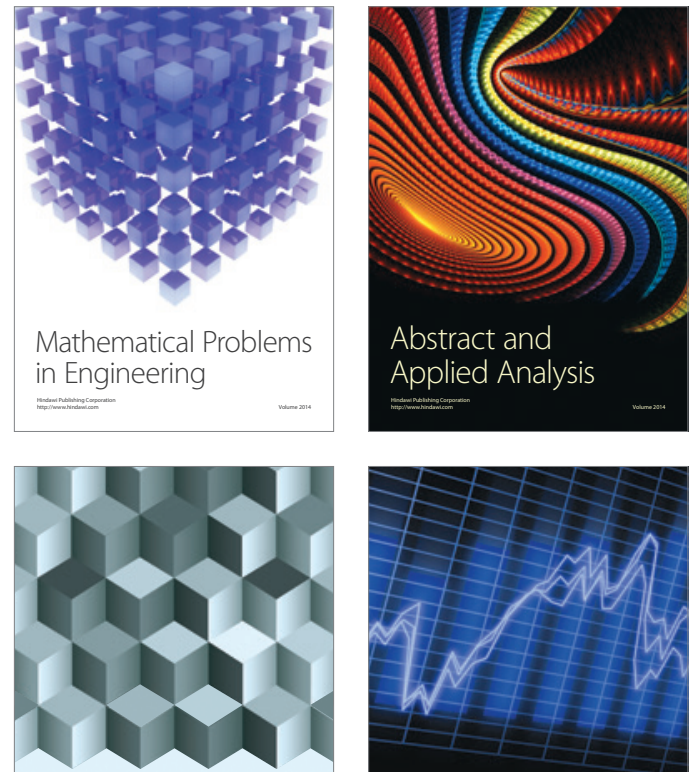

Journal of

Function Spaces

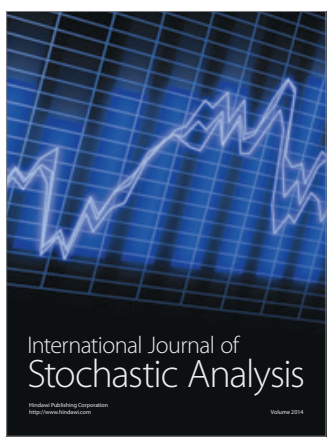

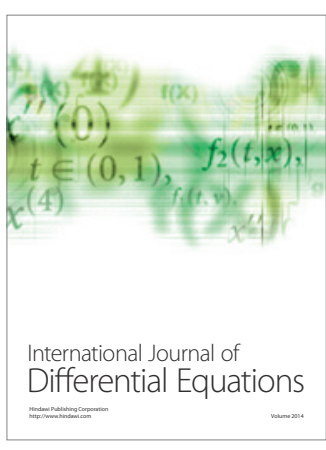
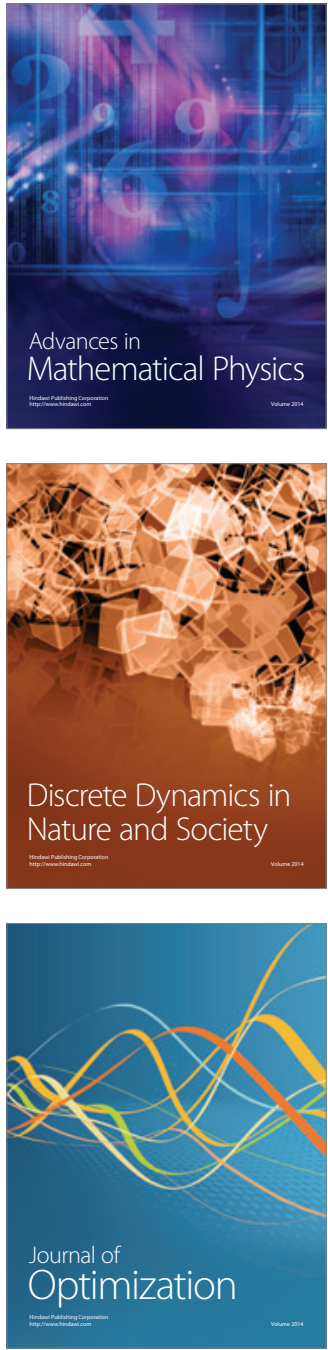